\title{
Confidence of Extension Staff in Akwa Ibom State Agricultural Development Programme
}

\author{
Ekumankama A. $\mathbf{O}^{1}$. and A.C. Anyanwu. ${ }^{2}$ \\ ${ }^{1}$ Department of Rural Sociology and Extension, \\ Michael Okpara University of Agriculture, Umudike. \\ 2. Department of Agricultural Extension, \\ University of Nigeria, Nsukka.
}

\begin{abstract}
This study assessed the organizational confidence of extension staff in Akwa lbom state agricultural development programme (AKADEP). The study also determined the relationships between selected personal characteristics and organizational confidence variables of the extension staff. A sample of ninety (90) randomly selected respondents provided information used for the study. Percentages, mean scores and Pearson correlation coefficient were employed in the analysis of data. Majority of the extension agents (EAs), block extension agents (BEAs), block extension supervisors (BESs), and zonal extension officers (ZEOs) were sometimes satisfied with AKADEP as their organization. Age, household size, and years of extension experience of EAs were strong indicators of organizational confidence. Age, level of formal education, household size and extension experience of BEAs were strong predicators of organizational confidence. Age, level of formal education, household size and extension experience of BESs were significantly associated with organizational confidence. Age, household size and years of extension experience of ZEOs were strong indicators of organizational confidence. Policies that would make good and balanced working conditions to be prevalent in AKADEP should be designed. This will promote organizational confidence of extension staff which, in turn, will boost their job performance and ultimately the performance of AKADEP as an extension agency.
\end{abstract}

\section{INTRODUCTION}

Nigeria is endowed with abundant natural resources. The agricultural potential of the country is high. One of the most effective means of transforming the potential agricultural resources into sustained agricultural development is effective agricultural extension service (NAERLS, 1997). Effective agricultural extension service depends largely on the effectiveness of frontline extension staff, namely extension agents (EAs), block extension agents (BEAs), and extension supervisors (BEs), who have the mandate to train the farming population. The effectiveness of these crops of workers in turn depends partly on the extent of satisfaction they have with every aspect of the organization. In other words, first-rate quality job performance of field extension personnel is partly dependent on the organizational confidence of these workers. 
Employee confidence in an organization could be measured in two aspects, viz, redressal of grievances, and fairness of supervisor's dealings, that is, the degree of satisfaction a worker gets from his dealings with his supervisor (Patel, 1983). Employee grievances, which are dissatisfactions that a staff has against management or dissatisfactions felt by a worker in connection with his work, can be a major reason for poor job performance of staff (Morgan, 1982).

Individual grievances can arise as a result of one employee feeling aggrieved. A staff that feels he has a grievance against a manager, a supervisor or against the organization as a whole is an unhappy worker and an unhappy worker cannot do effective work. He becomes depressed, his morale is low and as a consequence his efficiency reduces. Collective grievances may arise from alleged illtreatment of an employee, generally a union member or from a disagreement between the local union representative and management over the interpretation or non implementation of the collective agreement. A grievance, whether real or imaginary, can be the source and the reason for poor job performance of staff (Morgan, 1982).

The characteristics of extension personnel may affect (favour or disfavour) their level of confidence in extension organization. The personal characteristics include age, level of formal education and years of extension experience among others.

The questions which need to be addressed are the organizational confidence of extension personnel and their personal characteristics as they relate to organizational confidence. What is the level of organizational confidence of extension staff? What are the relationships between the personal characteristics of the extension workers and their level of confidence in the extension agency? These questions are relevant to effective agricultural extension services and sustainable agricultural development in general. To provide solution to these questions, this study was designed to assess the organizational confidence of extension staff at the zonal level in Akwa lbom state agricultural development programme (ADP), as well as determine the relationship between selected personal characteristics and the organizational confidence variables of the extension staff.

\section{METHODOLOGY}

The study was carried out in Akwa Ibom State of Nigeria. The state is situated within the humid zone and occupies the south east corner of Nigeria (Akpabio et al. 2002; Ekong and Olowu, 2002). The target population for this study was the agricultural extension staff at the zonal level in Akwa lbom state ADP. They are the ZEOs, BESs, BEAs, and EAs.

Multi-stage random sampling procedure was used in the selection of the agricultural zones, blocks, and circles. The first stage involved simple random selection of two agricultural zones in the state under study. Ikot Ekpene and Uyo zones were selected. The ZEOs whose zones were selected served as respondents. The second stage involved simple random selection of seven blocks from each of the agricultural zones. The BESs and BEAs whose blocks were selected served as respondents. The third stage involved simple random sampling of five circles from each of the blocks. The EAs whose circles were selected served as respondents. This gave a total of 2 ZEOs, 14 BESs, 14 BEAs and 70 EAs. Altogether, one hundred (100) respondents made up the sample size for the study. However, 90 copies of 
questionnaire $(2,4,12$, and 62 copies of questionnaire from ZEOs, BESs, BEAs and EAs, respectively) were found suitable for use in the analysis.

Data were collected through the use of structured questionnaire schedule. Four sets of questionnaire were used to elicit information from EAs, BEAs, BESs, and ZEOs. Questionnaire for the four groups of respondents were designed to collect data on their personal characteristics and organizational confidence.

To assess the organizational confidence of the extension staff, each of the sampled extension staff was asked to indicate the degree of satisfaction he/she derived in each of the 14 organizational confidence statements or items on a five point Likert-type scale. The five points on the scale were graded as follows: 1=Very Dissatisfied, 2=Dissatisfied, 3=Sometimes Satisfied, 4=Satisfied and $5=$ Very Satisfied. The mean degree of satisfaction for each of the 14 different organizational confidence statements or items for EAs, BEAs, BESs, and ZEOs was calculated by dividing the total satisfaction score by the number of respondents respectively. The organizational confidence level for each group of respondents was computed by dividing the grand mean satisfaction score of each group by number of the organizational confidence items (14).

Percentage and mean scores were utilized for data analysis. The correlation statistics was used for determining the relationship between selected personal characteristics and organizational confidence variables of extension staff at 0.05 level of significance.

\section{RESULT AND DISCUSSION}

Information was collected on the age, level of formal education, household size, and years of extension experience of the four groups of respondents in order to determine the relationships between the personal characteristics and organizational confidence of these respondents. The percentage scores of the selected personal characteristics are briefly summarized below. The organizational confidence of EAs, BEAs, BESs, and ZEOs are presented in Tables 1 to 4 respectively. The relationships between the selected personal characteristics and organizational confidence variables of the four groups of respondents are tested in Table 5, 6, 7 and 8.

\section{Personal Characteristics}

About $60.0 \%$ of the EAs compared with $67.0 \%$ of the BEAs were in the age range from 30-39 years. Sixty four percent of the BESs fell within the age bracket of 40-49 years. Fifty percent of the ZEOs were in the age range from $40-49$ years, while the remaining $50.0 \%$ were between 50 and 59 years. A greater proportion of the groups of respondents were in their economically active years (20-49 years). Ideally, young officers will be able to put in more years of productive service if the conditions of service are good for them (Ekumankama, 1994).

Majority of the EAs. (63.0\%) BEAs (75.0\%), and BESs $(78.6 \%)$ have higher national diploma (HND) certificate and/or above respectively. All the ZEOs $(100.0 \%)$ have HND certificate.

Most of the EAs (75.8\%), BEAs (66.7\%), and BESs $(64.3 \%)$ had between 1 and 5 members in their respective households. Fifty percent of the ZEOs had between 6 and 10 members in their households, while the remaining $50.0 \%$ had between 11 and 15 household members. 
The EAs acquired extension experience that ranged from 1 to 20 years with $61.3 \%$ of them having 1 to 5 years of service. Majority of the BEAs $(91.7 \%)$ had between 1 and 5 years experience in extension work. The BESs acquired extension experience that ranged from 6 to 25 years with $28.6 \%, 28.4 \%$ and $35.7 \%$, of them having 6 to 10 years, 11 to 15 years, and 16 to 20 years of service, respectively. Fifty percent of the ZEOs had between 21 and 25 years experience in extension work, while another $50.0 \%$ had acquired between 31 and 35 years experience in extension work. The survey shows that the ZEOs were generally more experienced in extension work than the EAs, BEAs and BESs. This result could be explained by the fact that the ZEOs are senior officers who reached that level by promotion from EA to BES to ZEO. Therefore, it naturally follows that higher officers have put in more years in most cases.

\section{Organizational Confidence of Extension Agents in Akwa lbom State ADP}

Entries in Table 1 indicate the means of the organizational confidence indices for the EAs in Akwa Ibom state ADP. The table reveals that the EAs were mostly satisfied with the level of interaction between them and their supervisors $(\bar{x}=4.26)$. This was followed by methods of human relationships $(\bar{x}=3.42)$, patterns of role clarification $(\bar{x}=3.11)$, and lines of organizational communication $(\bar{x}=3.10)$. Effective interaction between workers and their supervisors and cordial relationships among employees are essential factors in a work environment. This is because they will increase the probability that workers will be satisfied with their roles, have more confidence in the organization, and perform more effectively.

The grand mean organizational confidence was 35.09 , while the organizational confidence level was 3.00 implying that majority of the EAs were sometimes satisfied with the Akwa Ibom state ADP as an organization.

\section{TABLE 1: Confidence of the Extension Agents in Akwa Ibom State ADP ( $N=62)$}

\section{Organizational Confidence Indices}

$X$ satisfaction score

The level of interaction between you and

your supervisor

4.26

Timeliness of salary payment

2.27

Provision of incentives

1.29

Promotion and appraisal exercise

1.65

Concern for the staff social welfare

1.71

Provision of basic logistics including working kit

1.60

Coordination and supervision techniques being used

2.58

Monitoring and evaluation system

2.84

Interpretation of collective bargaining contract or

personnel policy

2.11

Channels for adjustment or redressal of grievances 2.18

Lines of organizational communication

3.10

Methods of human relationships

3.42

Performance feedback

2.97

Patterns of role clarification

3.11

Grand mean ( $\mathrm{X}$ ) organizational confidence score

$=$

$=2.51 \approx 3.00$

35.09

Organizational Confidence Level 
Journal of Agricultural Extension

Vol. 12 (1) June, 2008

\section{Organizational Confidence of Block Extension Agents in Akwa Ibom State ADP}

Table 2 indicates the means of the organizational confidence indices for the BEAs in Akwa lbom state ADP. The BEAs were mostly satisfied with the level of interaction between them and their immediate supervisors $(\bar{x}=4.50)$. Next to this was performance feedback $(\bar{x}=3.58)$, followed by patterns of role clarification $(\bar{x}=3.50)$. This was followed by methods of human relationships $(\bar{x}=3.42)$. The nature of relationships with one's supervisor and colleagues affect the level of confidence a worker has on his organization. Proper clarification of an employee's role is necessary if role conflict is to be avoided. According to Mmaduakonam (1997), role conflict exists when a worker in a particular work role is torn by conflicting job demands or is doing things he really does not want to do or does not think are part of the job specification. Role conflict will obviously lower the job satisfaction of an employee and ultimately the level of confidence he has in his organization.

The grand mean organizational confidence was 37.16, while the organizational confidence level was $2.65 \approx 3.00$. These findings imply that most of the BEAs were sometimes satisfied with the Akwa lbom state ADP as an organization.

\section{TABLE 2: Confidence of the Block Extenstion Agents in Akwa Ibom State ADP $(\mathrm{N}=12)$}

\section{Organizational Confidence Indices}

The level of interaction between you and your Supervisor

X Satisfaction Score

Timeliness of salary payment

4.50

Provision of incentives

2.67

Promotion and appraisal exercise

1.83

Concern for the staff social welfare

1.33

Provision of basic logistics including working kit

1.92

Coordination and supervision techniques being used

1.67

Monitoring and evaluation system

2.67

Interpretation of collective bargaining contract or personnel policy

2.83

Channels for adjustment or redressal of grievances

2.08

Lines of organizaional communication

2.58

Methods of human relationships

2.58

Performance feedback

Patterns of role clarification

Grand mean $\overline{(X)}$ Organizational confidence score

3.50

Organizational confidence level

$=37.16$
$=2.65 \sim 3.00$

\section{Organizational Confidence of Block Extension Supervisors in Akwa Ibom State ADP}

Entries in Table 3 indicate the means of the organizational confidence indices for the BESs in Akwa lbom state ADP. The BESs were mostly satisfied with the level of interaction between them and their supervisors $(\bar{x}=3.86)$. Next to this were lines of organizational communication $(\bar{x}=3.29)$. This was followed by monitoring and evaluation system $(\bar{x}=3.21)$, methods of human relationships $(\bar{x}=3.21)$, performance feedback $(\bar{x}=3.21)$, and patterns of role clarification $(\bar{x}=3.07)$. 
These findings are contrary to an earlier finding that alienation between the management and the workers, lack of interpersonal relationships and quarrels are characteristics of most organizations and industrial setup in Nigeria (Maduakonam, 1997)

Good interpersonals between a worker and his supervisor and counterparts are central factor in individual and organizational health (Mmaduakonam, 1997). Good communication with management, colleagues and subordinates makes an organization to maintain goodwill, grows and waxes (Nwachukwu, 1988). The grand mean organizational confidence was 37.43 , while the organizational confidence level was 3.00 , implying that majority of the BESs were sometimes satisfied with the Akwa Ibom state ADP as an organization.

\section{TABLE 3: Confidence of the Block Extension Supervisors in Akwa Ibom state} ADP ( $N=14)$

Organizational Confidence Indices

$\bar{x}$ Satisfaction

Score

The level of interaction between you and your

supervisor

Timeliness of salary payment

Provision of incentives

Promotion and appraisal exercise

Concern for the staff social welfare

Provision of basic logistics including working kit

Coordination and supervision techniques being used

Monitoring and evaluation system

Interpretation of collective bargaining contract or personnel

policy

Channels for adjustment or redressal of grievances

Lines of organizational communication

Methods of human relationships

Performance feedback

Patterns of role clarification

Grand mean (X) Organizational Confidence Score

37.43

Organizational Confidence Level

$=2.67 \approx 3.00$


Journal of Agricultural Extension

Vol. 12 (1) June, 2008

\section{Organizational Confidence of Zonal Extension Officers in Akwa Ibom state ADP}

The means of the organizational confidence indices for the ZEOs in Akwa lbom state ADP are presented in Table 4. The ZEOs were mostly satisfied with the level of interaction between them and their supervisor $(\bar{x}=4.00)$, lines of organizational communication $(\bar{x}=4.00)$ and methods of human relationships $(\bar{x}=4.00)$. The table also reveals that the mean satisfaction scores for monitoring and evaluation system, performance feedback, patterns of role clarification, timeliness of salary payment, coordination and supervision techniques being used, and interpretation of collective bargaining contract or personnel policy were $3.50,3.50,3.50,3.00$, and 3.00 respectively. A worker's behaviour is influenced by interactions with people around him. Good interpersonal relationships at work can enhance the organizational confidence of workers. A good organizational climate is set when the leader sets the pace for open communication by encouraging subordinates to be frank, by soliciting information and sending out feedback (Nwachukwu, 1988).

The grand mean organizational confidence was 43.50, while the level of organizational confidence was 3.00. These findings imply that the ZEOs were sometimes satisfied with the Akwa lbom state ADP as an organization.

TABLE 4: Confidence of the Zonal Extension Officers in Akwa lbom state ADP Organizational Confidence Indices

$X$ Satisfaction Score

The level of interaction between you and your supervisor

4.00

Timeliness of salary payment

Provision of incentives

Promotion and appraisal exercise

Concern for the staff social welfare

Provision of basic logistics including working kit

Coordination and supervision technique being used

Monitoring and evaluation system

Interpretation of collective bargaining contract or personnel policy

Channels for adjustment or redressal of grievance

Lines of organizational communication

4.00

Methods of human relationships

Performance feedback

Patterns of role clarification

Grand mean $(\bar{X})$ organizational confidence score $=\quad 43.50$

Organizational confidence level

$3.11 \approx 3.00$




\section{Relationship between Selected Personal Characteristics and Organizational Confidence Variables of Extension Staff}

Four personal characteristics, namely age, level of formal education, household size and years of extension experience were selected and their relationships with the organizational confidence variables of the extension staff were determined using Pearson correlation. Four hypotheses stated in the null form were tested and the results shown in Tables 5 to 8 .

\section{Relationship between Selected Personal Characteristics and Organizational Confidence Variables of Extension Agents in Akwa lbom State ADP}

The first hypothesis states that there is no significant relationship between selected personal characteristics and organizational confidence variables of extension agents in Akwa Ibom state ADP. Data in Table 5 reveal that level of formal education of EAs was negatively and significantly correlated with timeliness of salary payment $(r=-$ 0.31 ), methods of human relationships $(r=-.025)$ and patterns of role clarification ( $r=-$ 0.26 ). The implication of this finding is that the higher the level of formal education received by the EAs, the less satisfied they were with timeliness of salary payment, methods of human relationships and patterns of role clarification and thus, the less they developed confidence in the organization.

The table further shows that household size of EAs was positively and significantly correlated with timeliness of salary; payment $(r=0.26)$, implying that the larger the household size of the EAs, the more satisfied they were with the time they received their salaries and hence, the more they developed confidence in the organization. Extension experience of EAs was positively and significantly correlated with performance feedback $(r=0.33)$, meaning that the more extension experience the EAs acquired, the more satisfied they were with performance feedback and thus, the more they developed confidence in the organization. Age expressed a non-significant relationship with all the organizational confidence variables, implying that age was not significantly associated with organizational confidence of EAs in Akwa lbom state ADP. 
Journal of Agricultural Extension

Vol. 12 (1) June, 2008

TABLE 5: Pearson Correlation Analysis of the Relationship Between Selected Personal Characteristics and Organizational Confidence Variables of Extension Agents in Akwa Ibom State ADP ( $N=62)$

Personal Characteristics Variables

Organizational Confidence

\begin{tabular}{|c|c|c|c|c|c|c|c|c|c|c|c|c|c|c|}
\hline & 1 & 2 & 3 & 4 & 5 & 6 & 7 & 8 & 9 & 10 & 11 & 12 & 13 & \\
\hline Age & -0.09 & 0.14 & -0.02 & 0.10 & -0.03 & -0.05 & 0.01 & 0.18 & 0.02 & -0.08 & 0.21 & 0.22 & 0.12 & 0.09 \\
\hline $\begin{array}{l}\text { Level of formal } \\
\text { education }\end{array}$ & -0.03 & $-0.31^{*}$ & -0.13 & -0.05 & 0.07 & -0.05 & 0.09 & -0.24 & -0.02 & 0.04 & -0.12 & $-0.25^{*}$ & -0.06 & \\
\hline Household size & 0.21 & $0.26^{*}$ & 0.08 & 0.01 & -0.23 & -0.10 & 0.18 & 0.17 & -0.02 & 0.06 & 0.21 & 0.00 & 0.03 & 0.01 \\
\hline $\begin{array}{l}\text { Extension } \\
\text { experience }\end{array}$ & -0.12 & -0.06 & 0.13 & 0.09 & 0.01 & 0.10 & 0.11 & 0.14 & 0.17 & 0.13 & 0.11 & 0.11 & $\underset{*}{0.35}$ & 0.07 \\
\hline
\end{tabular}

*Significant at $P<0.05$

Key:

$1=$ The level of interaction between you and your supervisor

2 = Timeliness of salary payment

$3=$ Provision of incentives

$4=$ Promotion and appraisal exercise

$5=$ Concern for the staff social welfare

$6=$ Provision of basic logistics including working kit

$7=$ Coordination and supervision techniques being used

$8=$ Monitoring and evaluation system

$9=$ Interpretation of collective bargaining contract or personnel policy

$10=$ Channels for adjustment or redressal of grievances

$11=$ Lines of organizational communication

$12=$ Methods of human relationships

$13=$ Performance feedback

$14=$ Patterns of role clarification 


\section{Relationship between Selected Personal Characteristics and Organizational Confidence Variables of Block Extension Agents in Akwa lbom State ADP}

The second hypothesis states that there is no significant relationship between selected personal characteristics and organizational confidence variables of block extension agents in Akwa lbom state ADP. Data in Table 6 indicate that age was negatively and significantly correlated with the level of interaction between BEA and her supervisor $(r=-0.75)$, promotion and appraisal exercise $(r=-0.28)$, concern for the staff social welfare $(r==-0.31)$, provision of basic logistics including working kit $(r=-$ $0.46)$, coordination and supervision techniques being used ( $r=-0.25)$ and lines of organizational communication $(r=-0.33)$. This finding implies that the older the BEAs, the less satisfied they were with the level of interaction between them and their supervisor and the other aforementioned organizational confidence variables and hence, the less they developed confidence in the organization. Age was positively and significantly correlated with timeliness of salary payment $(r=0.90)$, performance feedback $(r=0.39)$ and patterns of role clarification $(r=0.42)$. This implication of this finding is that the older the BEAs, the more satisfied they were with these organizational confidence variables, thus the more they developed confidence in the organization.

The table further shows that level of formal eduation was negatively and significantly correlated with the level of interaction between BEA and her supervisor $(r=-0.30)$, provision of incentives $(r=-0.29)$, concern for the staff social welfare $(r=-$ $0.42)$, provision of basic logistics including working kit $(r=-0.69)$, interpretation of collective bargaining contract or personnel policy $(r=-0.36)$, methods of human relationships $(r=-0.27)$, and patterns of role clarification $(r=-0.30)$. This means that the higher the level of formal education received by the BEAs, the less satisfied they were with these organizational confidence variables and therefore, the less confidence they developed in the organization. The level of formal education was positively and significantly correlated with monitoring and evaluation system $(r=0.25)$ and channels for adjustment or redressal of grievances $(r=0.25)$. This finding imply that the higher the level of formal education received by the BEAs, the more satisfied they were with these organizational confidence variables and hence, the more they developed confidence in the organization

The size of the household was positively and significantly correlated with the level of interaction between BEA and her supervisor $(r=0.26)$, timeliness of salary payment $(r=0.55)$, promotion and appraisal exercise $(r=0.33)$, coordination and supervision techniques being used $(r=0.45)$, monitoring and evaluation system $(r=0.77)$, channels for adjustment or redressal of grievances $(r=0.32)$ and lines of organizational communication $(r=0.32)$, respectively. This finding implies that the larger the household size of the BEAs, the more satisfied they were with the aforementioned organizational confidence variables. This, in turn, ensured development of more confidence by the BEAs in their organization. Household size was negatively and significantly correlated with provision of basic logistics including working kit $(r=-0.43)$ and interpretation of collective bargaining contract or personnel policy $(r=-0.40)$, implying that the larger the household size of the BEAs, the less satisfied they were with provision of basic logistics including working kit and interpretation of collective bargaining contract or personnel policy and hence, the less they developed confidence in the organization. 
Table 6 also reveals that extension experience was negatively and significantly correlated with promotion and appraisal exercise $(r=-0.31)$, concern for the staff social welfare $(r=-0.50)$, and provision of basic logistics including working kit $(r=-0.41)$ respectively. The implication of this finding is that the more experience the BEAs acquired on extension work, the less satisfied they were with these organizational confidence variables; thus, the less they developed confidence in the organization. The extension experience of the BEAs was positively and significantly correlated with timeliness of salary payment $(r=0.26)$ and monitoring and evaluation system $(r=0.27)$, implying that the more experience the BEAs acquired on extension work, the more satisfied they were with the time they received their salaries and monitoring and evaluation system, thus the more they developed confidence in the organization. 
Journal of Agricultural Extension

Vol. 12 (1) June, 2008

TABLE 6: Pearson Correlation Analysis of the Relationship between Selected Personal Characteristics and Organizational Confidence Variables of Block Extension Agents in Akwa lbom State ADP ( $N=12)$

\begin{tabular}{|c|c|c|c|c|c|c|c|c|c|c|c|c|c|c|}
\hline \multirow{2}{*}{$\begin{array}{l}\text { Personal } \\
\text { Characteristics }\end{array}$} & \multicolumn{14}{|c|}{ Organizational Confidence Variables } \\
\hline & 1 & 2 & 3 & 4 & 5 & 6 & 7 & 8 & 9 & 10 & 11 & 12 & 13 & 14 \\
\hline Age & $-0.75^{*}$ & $0 . .90^{*}$ & $-0 . .20$ & $-0.28^{*}$ & $-0.31^{*}$ & $-0.46^{*}$ & $-0.25^{*}$ & 0.05 & -0.04 & -0.14 & $0.33^{*}$ & -0.10 & $0.39 *$ & $0.42^{*}$ \\
\hline $\begin{array}{l}\text { Level of formal } \\
\text { education }\end{array}$ & $-0.30^{*}$ & -0.09 & $-0.29^{*}$ & -0.05 & $-0.42^{*}$ & $-0.69^{*}$ & 0.12 & $0.25^{*}$ & $0.36^{*}$ & $0.25^{*}$ & 0.12 & $-0.27^{*}$ & -0.20 & $-0.30^{*}$ \\
\hline Household size & $0.26^{*}$ & $0.55^{*}$ & 0.22 & 0.33 & -0.06 & $-0.43^{*}$ & $0.45^{*}$ & $0.77^{*}$ & $-0.40^{*}$ & $0.32^{*}$ & $0.32^{*}$ & 0.18 & 0.21 & 0.09 \\
\hline $\begin{array}{l}\text { Extension } \\
\text { Experience }\end{array}$ & -0.15 & $0.26^{*}$ & 0.00 & $-0.31^{*}$ & $-0.50^{*}$ & $-0.41^{*}$ & 0.17 & $0.27^{*}$ & 0.23 & 0.05 & 0.18 & -0.15 & -0.23 & -0.15 \\
\hline
\end{tabular}

*Significant at $P<0.05$

KEY:

$1=$ The level of interaction between you and your supervisor

2 = Timeliness of salary payment

$3=$ Provision of incentives

$4=$ Promotion and appraisal exercise

$5=$ Concern for the staff social welfare

$6=$ Provision of basic logistics including working kit

$7=$ Coordination and supervision techniques being used

$8=$ Monitoring and evaluation system

$9=$ Interpretation of collective bargaining contract or personnel policy

$10=$ Channels for adjustment or redressal of grievances

$11=$ Lines of organizational communication

$12=$ Methods of human relationships

$13=$ Performance feedback

$14=$ Patterns of role clarification 
Journal of Agricultural Extension

Vol. 12 (1) June, 2008

\section{Relationship between Selected Personal Characteristics and Organizational Confidence variables of Block Extension Supervisors in Akwa Ibom State ADP}

The third hypothesis states that there is no significant relationship between selected personal characteristics and organizational confidence variables of block extension supervisors in Akwa Ibom state ADP. According to Table 7, age was positively and significantly correlated with the level of interaction between BES and the supervisor $(r=0.36)$, provision of incentives $(r=0.31)$, promotion and appraisal exercise $(r=0.29)$, coordination and supervision techniques being used ( $r=0.37)$, interpretation of collective bargaining contract or personnel policy $(r=0.30)$, channel for adjustment or redressal of grievances $(r=0.38)$ and lines of organizational communication $(r=0.53)$. This finding implies that the older the BESs, the more satisfied they were with the aforementioned organizational confidence variables, thus, the more they developed confidence in the organization.

Data in Table 7 reveal that level of formal education was negatively and significantly correlated with the level of interaction between BES and the supervisor ( $r=-$ $0.66)$, provision of incentives ( $r=-0.25)$, coordination and supervision techniques being used $(r=-0.43)$, interpretation of collective bargaining contract or personnel policy ( $r=-$ $0.26)$, channel for adjustment or redressal of grievances $(r=-0.55)$, lines of organizational communication $(r=-0.62)$, methods of human relationship $(r=-0.56)$, performance feedback $(r=-0.36)$ and patterns of role clarification $(r=-0.37)$, respectively. The implication of this finding is that the higher the level of formal education received by the BESs, the less satisfied they were with the aforementioned organizational confidence variables, thus, the less confidence they developed in their organization. Level of formal education was positively and significantly correlated with concern for the staff social welfare $(r=0.37)$, implying that the higher the level of formal education received by the BESs, the more satisfied they were with concern for the staff social welfare and hence, the more confidence they developed in their organization.

Table 7 indicates that household size was positively and significantly correlated with the level of interaction between BES and the supervisor ( $r=0.54)$, coordination and supervision techniques being used $(r=0.44)$, channels for adjustment or redressal of grievances $(r=0.68)$, lines of organizational communication $(r=0.90)$, methods of human relationships $(r=0.54)$ and patterns of role clarification $(r=0.54)$, respectively. The implication of this finding is that the larger the household size of the BESs, the more satisfied they were with the aforementioned organizational confidence variables and hence, the more they developed confidence in the organization. Household size was negatively and significantly correlated with concern for the staff social welfare, implying that the larger the household size of the BESs, the less satisfied they were with concern for the staff social welfare, thus, the less they developed confidence in the organization.

Table 7 shows that extension experience was positively and significantly correlated with provision of basic logistics including working kit ( $r=0.45)$, coordination and supervision techniques being used $(r=0.30)$, channel for adjustment or redressal of grievances $(r=0.32)$, lines of organizational communication $(r=0.32)$ and patterns of role clarification $(r=0.28)$, respectively. This finding implies that the more experience the BESs acquired on extension work, the more satisfied they were with these organizational confidence variables, thus, the more they developed confidence in the 
organization. Extension experience was negatively and significantly correlated with monitoring and evaluation system, meaning that the more experience the BESs acquired on extension work, the less satisfied they were with monitoring and evaluation system and hence, the less they developed confidence in the organization. 
Journal of Agricultural Extension

Vol. 12 (1) June, 2008

TABLE 7: Pearson Correlation Analysis of the the Relationship Between Selected Personal Characteristics and Organizational Confidence Variables of Block Extension Supervisors in Akwa Ibom State ADP (N=14)

\begin{tabular}{|c|c|c|c|c|c|c|c|c|c|c|c|c|c|c|}
\hline \multirow{3}{*}{$\begin{array}{l}\text { Personal } \\
\text { Characteristics } \\
\text { Age }\end{array}$} & \multicolumn{14}{|c|}{ Organizational Confidence Variables } \\
\hline & 1 & 2 & 3 & 4 & 5 & 6 & 7 & 8 & 9 & 10 & 11 & 12 & 13 & 14 \\
\hline & $0.36^{*}$ & 0.19 & $0.31^{*}$ & $0.29 *$ & 0.11 & 0.14 & $0.37^{*}$ & 0.08 & $0.30 *$ & $0.38^{*}$ & $0.53^{*}$ & 0.22 & 0.02 & 0.11 \\
\hline $\begin{array}{l}\text { Level of formal } \\
\text { Education }\end{array}$ & $-0.66^{*}$ & -0.01 & $-0.25^{\star}$ & -0.22 & $0.37^{*}$ & 0.11 & $-0.43^{*}$ & -0.11 & $-0.26^{*}$ & $-0.55^{\star}$ & $-0.62^{*}$ & $-0.56^{*}$ & $-0.36^{*}$ & $-0.37^{*}$ \\
\hline Household size & $0.54^{*}$ & 0.20 & 0.11 & 0.10 & -0.35 & 0.06 & $0.44^{*}$ & -0.07 & -0.02 & $0.68^{*}$ & $0.90^{*}$ & $0.54^{*}$ & 0.22 & $0.54^{*}$ \\
\hline $\begin{array}{l}\text { Extension } \\
\text { Experience }\end{array}$ & 0.12 & 0.12 & 0.18 & 0.08 & 0.19 & $0.45^{*}$ & $0.30^{*}$ & $-0.26^{*}$ & -0.11 & $0.32^{*}$ & $0.32^{*}$ & 0.12 & 0.09 & $0.28^{*}$ \\
\hline
\end{tabular}

*Significant at $P<0.05$

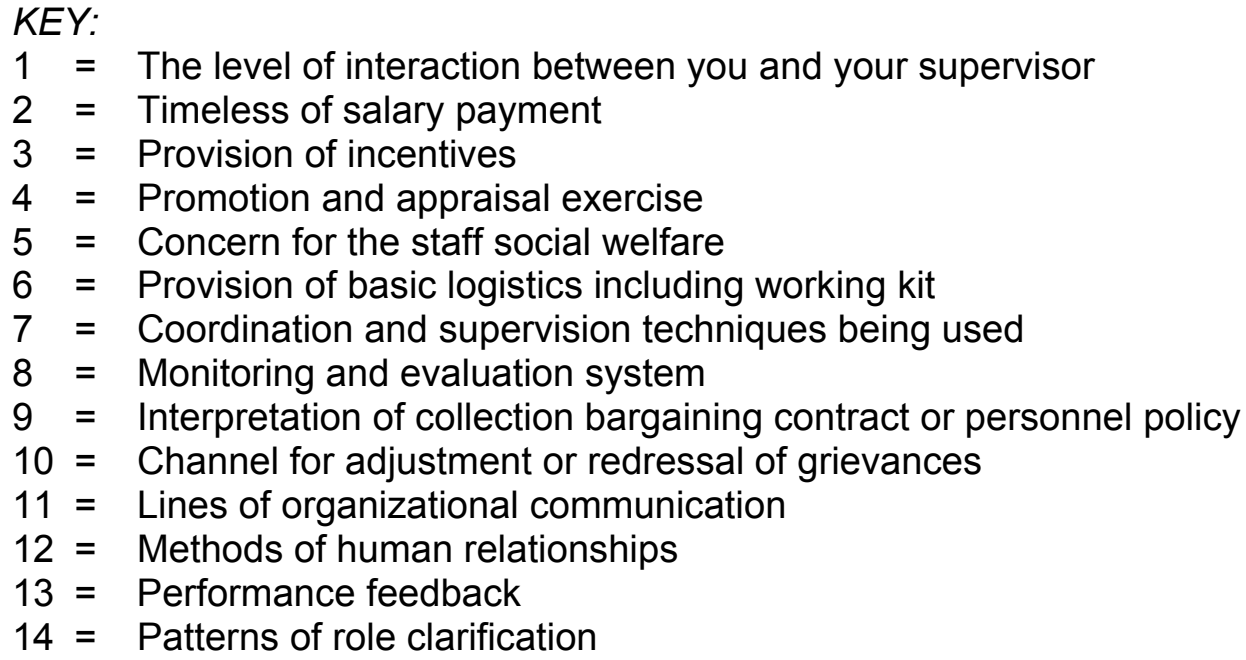




\section{Relationship between Selected Personal Characteristics And Organizational Confidence Variables of Zonal Extension Officers In Akwa Ibom State ADP}

The fourth hypothesis states that there is no significant relationship between selected personal characteristics and organizational confidence variables of zonal extension officers in Akwa Ibom state ADP. Data on the relationship between selected personal characteristics and organizational confidence variables of zonal extension officers in Akwa Ibom state ADP are presented in Table 8. Age was found positively and significantly correlated with the provision of incentives $(r=1.00)$ and performance feedback ( $r=1.00)$ implying that the older the ZEOs, the more satisfied they were with provision of incentives and performance feedback, thus, the more they developed confidence in the organization. Age was also negatively and significantly correlated with concern for the staff social welfare $(r=-1.00)$, provision of basic logistics including working kit $(r=-1.00)$, monitoring and evaluation system $(r=-1.00)$, channels for adjustment or redressal of grievances $(r=-1.00)$ and patterns of role clarification $(r=-$ 1.00), respectively. This means that the older the ZEOs, the less satisfied they were with these organizational confidence variables and hence, the less they developed confidence in the organization.

The table indicates that household size was negatively and significantly correlated with provision of incentives $(r=-1.00)$, and performance feedback $(r=-1.00)$. This finding implies that the larger the household size of the ZEOs, the less satisfied they were with provision of incentives and performance feedback and thus, the less they developed confidence in the organization. Household size was also positively and significantly correlated with concern for the staff social welfare $(r=1.00)$, provision of basic logistics including working kit $(r=1.00)$, monitoring and evaluation system $(r=1.00)$, channels for adjustment or redressal of grievance $(r=1.00)$, and patterns of role clarification $(r=1.00)$, respectively.

The implication of this finding is that the larger the household size of the ZEOs, the more satisfied they were with these organizational confidence variables and hence, the more they developed confidence in the organization.

Table 8 shows that extension experience of the ZEOs was positively and significantly correlated with provision of incentives $(r=1.00)$, and performance feedback $(r=1.00)$. This finding implies that the more experience the ZEOs acquired in extension work, the more satisfied they were with provision of incentives and performance feedback and thus, the more they developed confidence in the organization. Also, extension experience was negatively and significantly correlated with concern for the staff social welfare $(r=-1.00)$, provision of basic logistics including working kit $(r=-1.00)$, monitoring and evaluation system $(r=-1.00)$, channels for adjustment or redressal of grievances $(r=-1.00)$, and patterns of role clarification ( $r=-$ $1.00)$, respectively. This means that the more experience the ZEOs acquired on extension work, the less satisfied they were with these organizational confidence variables and hence, the less they developed confidence in the organization.

The hypothesis of no significant relationship between selected personal characteristics and organizational confidence variables of ZEOs in Akwa lbom state ADP was rejected on the basis of the above findings. 
Journal of Agricultural Extension

Vol. 12 (1) June, 2008

TABLE 8: Pearson Correlation Analysis of the Relationship Between Selected Personal Characteristics and Organizational Confidence Variables of Zonal Extension Officers in Akwa Ibom State ADP ( $\mathbf{N}=2$ )

\begin{tabular}{|l|l|l|l|l|l|l|l|l|l|l|l|l|l|l|}
\hline & \multicolumn{9}{|c|}{ Organizational Confidence Variables } \\
\cline { 2 - 11 } $\begin{array}{l}\text { Personal } \\
\text { Characteristics }\end{array}$ & $\mathbf{1}$ & $\mathbf{2}$ & $\mathbf{3}$ & $\mathbf{4}$ & $\mathbf{5}$ & $\mathbf{6}$ & $\mathbf{7}$ & $\mathbf{8}$ & $\mathbf{9}$ & $\mathbf{1 0}$ & $\mathbf{1 1}$ & $\mathbf{1 2}$ & $\mathbf{1 3}$ & $\mathbf{1 4}$ \\
\hline Age & $\mathrm{A}$ & $\mathrm{a}$ & $1.00^{*}$ & $\mathrm{a}$ & $-1.00^{*}$ & $1.00^{*}$ & $\mathrm{a}$ & $1.00^{*}$ & $\mathrm{a}$ & $-1.00^{*}$ & $\mathrm{~A}$ & $\mathrm{a}$ & $1.00^{*}$ & $-1.00^{*}$ \\
\hline $\begin{array}{l}\text { Level of formal } \\
\text { education }\end{array}$ & $\mathrm{A}$ & $\mathrm{a}$ & $\mathrm{A}$ & $\mathrm{a}$ & $\mathrm{A}$ & $\mathrm{A}$ & $\mathrm{a}$ & $\mathrm{a}$ & $\mathrm{a}$ & $\mathrm{a}$ & $\mathrm{A}$ & $\mathrm{a}$ & $\mathrm{a}$ & $\mathrm{a}$ \\
\hline $\begin{array}{l}\text { Household } \\
\text { Size }\end{array}$ & $\mathrm{A}$ & $\mathrm{a}$ & $-1.00^{*}$ & $\mathrm{a}$ & $1.00^{*}$ & $1.00^{*}$ & $\mathrm{a}$ & $1.00^{*}$ & $\mathrm{a}$ & $1.00^{*}$ & $\mathrm{~A}$ & $\mathrm{a}$ & $-1.00^{*}$ & $1.00^{*}$ \\
\hline Extension experience & $\mathrm{A}$ & $\mathrm{a}$ & $1.00^{*}$ & $\mathrm{a}$ & $-1.00^{*}$ & $-1.00^{*}$ & $\mathrm{a}$ & $-1.00^{*}$ & $\mathrm{a}$ & $-1.00^{*}$ & $\mathrm{~A}$ & $\mathrm{a}$ & $1.00^{*}$ & $1.00^{*}$ \\
\hline
\end{tabular}

*Significant at $P<0.05$

${ }^{a}$ cannot be computed because one of the variables is constant KEY:

$1=$ The level of interaction between you and your supervisor

2 = Timeliness of salary payment

$3=$ Provision of incentives

$4=$ Promotion and appraisal exercise

$5=$ Concern for the staff social welfare

$6=$ Provision of basic logistics including working kit

$7=$ Coordination and supervision techniques being used

$8=$ Monitoring and evaluation system

$9=$ Interpretation of collective bargaining contract or personnel policy

$10=$ Channels for adjustment or redressal of grievances

$11=$ Lines of organizational communication

$12=$ Methods of human relationships

$13=$ Performance feedback

$14=$ Patterns of role clarification 


\section{CONCLUSION}

This study has shown that majority of the EAs, BEAs, BESs, and ZEOs in Akwa lbom state ADP were sometimes satisfied with ADP as their organization. Level of formal education, household size, and extension experience of EAs were significantly associated with organizational confidence. Age, level of formal education, household size and extension experience of BEAs were strong predicators of organizational confidence. Age, level of formal education, household size and extension experience of BESs were significantly associated with organizational confidence. Age, household size and extension experience of ZEOs were strong indicators of organizational confidence.

Policies should be designed toward ensuring good and balanced working conditions in AKADEP. This will promote the organizational confidence of the extension personnel and ultimately improving their job performance.

\section{References}

Akpabio, I.A., U.A. Asa and J.M. Akpan (2002), Analysis of Achievements and Constraints of the Akwa Ibom Women Cooperative Association, Nigerian Journal of Rural Sociology, 4(1):91-94.

Ekong, E.W. and T.A. Olowu (2002), Women's Access to Agricultural Production and Resources in Akwa Ibom State, Nigerian Journal of Rural Sociology, 4(1): 8590.

Ekumankama, O.O. (1994). The Contributions of the Agricultural Extension and Research Liaison Service (AERLS) of the National Root Crops Research Institute (NRCRI) Umudike to Technology Transfer in Abia State. M.Sc. Thesis, Department of Agricultural Extension, University of Nigeria, Nsukka.

Mmaduakonam, A.E. (1997), Occupational Stress: Counselling the Workers for Survival, Academic Publishing Company, Enugu.

Morgan, J. E. (1982), Administrative and Supervisory Management (Second Edition), Prentice-Hall, Inc. Englewood Cliffs.

NAERLS (1997), Evaluation of the Effectiveness and Impact of the Training and Visit Extension System in Nigeria, Research Report Submitted to Agricultural Projects Monitoring and Evaluation Unit (APMEU), Federal Department of Agriculture, Abuja.

Nwachukwu, C. C. (1988), Management Theory and Practice, Africana-Fep Publishers Ltd., Onitsha.

Patel, A.U. (1983), Evaluation of Extension Education Programme, Mimeo, Department of Agricultural Extension and Rural Development, University of Ibadan, Nigeria. 